DE DE GRUYTER

OPEN

DOI 10.1515/pesd-2015-0003

PESD, VOL. 9, no. 1, 2015

\title{
ACCESIBILITY TO BASIC URBAN SERVICES IN MBOUR CITY (SENEGAL): AN APPROACH BASED ON GEOGRAPHICAL INFORMATION SYSTEM
}

\section{Thiam Sokhna ${ }^{1}$, Roșu Lucian ${ }^{2}$, Faye Ousmane ${ }^{1}$, Niang Aminata Diène ${ }^{1}$, Muntele Ionel $^{2}$}

Key words: spatial inequalities, urban basic facilities, Mbour, accessibility.

\begin{abstract}
The uneven spatial distribution of basic facilities within urban areas is a major problem for developing countries like Senegal due to the emphasis of accessibility disparities and the use of this services. The efforts to quantify the problem and its consequences on people are constrained by the lack of satisfactory data and methods. The study seeks to examine the spatial accessibility to basic services (access to water, health, education, economic infrastructure and transportation services) in a very heterogeneous urban system and to highlight inequalities in access for improving the geographical accessibility and to ensure equity. The article explore the use of spatial analysis method (Closest Facility) to measure the potential accessibility to services and facilities in the city of Mbour. The analyses uses all the inhabited houses of the city as the potential demand. Results emphasis unequal access to basic urban services in the city and a center-periphery model with a high concentration of services around the city. The study demonstrates the utility of this method for the identification of disadvantaged areas, decision making and planning of basic services. It also provides paths for improving accessibility in urban areas with a high density of population.
\end{abstract}

\section{Introduction}

The coastline is an area that focuses complex problems regarding urban areas; due to the attraction it exerts, the agglomerations face many social problems (Toure, 2011). However, a coastal city is usual a city with problems as

1 Université Cheikh Anta Diop de Dakar, Sénégal, sokhna.thiam608@gmail.com

2 Université « Alexandru Ioan Cuza » de Iasi, Roumanie, luci_r2003@yahoo.com 
a result of its extension, caused by the influx of people from different areas which creates an increase for demand of basic urban facilities. One of frequently encountered problems in developing countries in general and Senegal in particular is access to basic urban facilities. Thus, the city of Mbour is no exception to this rule. Unlike other cities from the Central Senegal, Mbour faces an increase of population (due to a more dynamic economic activity based on fisheries, tourism and commerce) thus worsening the use of basic urban faculties. The fast extension of the city is another major problem. Nevertheless, the problem of access to basic urban facilities is still not correlated with urban extension, and demographic increasing. As a matter of fact, Vennnetier point out that in the cities of tropical Africa, the speed and magnitude of the demographic and spatial growth have not allowed the government to provide the agglomerations with all collective infrastructure needed for the day life of citizens (Vennetier, 1993).

In Senegal, access to basic urban facilities includes health, education, and access to water, transport and has always attracted the attention of the authorities. The access rate to these facilities increased from 54\% in 2009 to $79 \%$ nowadays (ANSD, Cartographie des services sociaux de base, 2012). Basic urban services are not even distributed across the population in the country in general and in the city of Mbour in particular. Access to these essential services for promoting human dignity, increase the quality of life and support sustainable livelihoods is one of the Millennium Development goals. Thus, improving their access is a way to achieve these development goals, which puts them at the base of any national strategy against poverty and socioeconomic development.

Despite the importance given by international organisms for the access to basic facilities at the World Summit for Social Development in May 1995 (Copenhagen), there is no study dealing with spatial accessibility for basic facilities in Mbour. Yet, it is clear that the use of services can only take place if they are physically accessible. Accessibility can be defined as the possibility for a place to be reached from other locations in different geographical locations. It involves two components: the offer (service) and potential demand (potential users)(Groza 2005). The current academic stream classifies accessibility into two distinct dimensions (potential or spatial and non-spatial) and three categories namely the: potential spatial accessibility, the actual spatial accessibility, potential-spatial accessibility and real-spatial accessibility (Guagliardo, 2004). The distance accessibility concerning the effective access to services refers to the probability or the possibility of access to services. As for the spatial accessibility, it focuses on the physical distance between supply and 
demand potential while aspatial access highlights socio-economic and demographic access (Ngamini Ngui and Apparicio 2011).

The main goal of the study is, therefore, to examine the spatial and potential accessibility to basic urban facilities in a growing average city and to identify inequalities in access to services. This will provide a method of identification of risk areas that can be used as a tool to aid decision-making and urban planning in Senegal and especially in Mbour. This will be achieved by using the Closest Facility method. The method takes into account both the supply (service) and potential demand (population) in the calculation of accessibility.

\section{Materials and methods}

\subsection{Presentation of the study area}

Established from 1920 on the Senegalese coast, the town of Mbour ranges from $17^{\circ} 02 \mathrm{~W}$ and $16^{\circ} 58 \mathrm{~W}$ longitude and $14^{\circ} 22 \mathrm{~N}$ and $14^{\circ} 26 \mathrm{~N}$ latitude. It is located in the northwest part of the Small Coast, $83 \mathrm{~km}$ from the capital on the Dakar-Kaolack major axis (Fig. 1). Mbour experienced a strong population growth in recent years. From 77168 inhabitants in 1988, the population grew to 223066 inhabitants in 2014 (ANSD, RGPH, projection de la population, 2012).

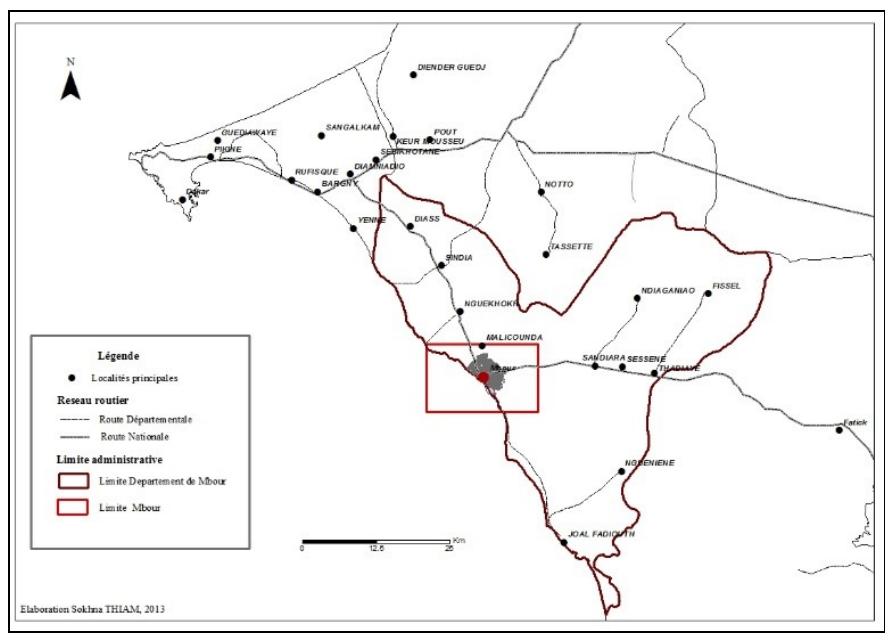

Fig.1 Mbour position inside of Senegal

Unnoficial estimations realized by the management of the municipality says that the current population is far higher that the projection for 2014 made on the basis of the last census in 2002. The population growth is naturally accompanied by a strong spatial expansion, especially in the recent years (from 
522,9 ha in 1978 to 1725 ha in 1999 (Ba 1991). This has resulted in an increase in the number of districts ( 10 in 2000 to 25 in 2010) according to data from the municipality. The town of Mbour is a receptive of migration flow from the interior of the country but also from small towns and villages from the surroundings. Mbour experienced a process of rapid urbanization. This type of urbanization is firstly related to its geographical position and then, the other economic activities (fishing and tourism). The map below (Fig. 2) shows the urban morphology and the extension process.

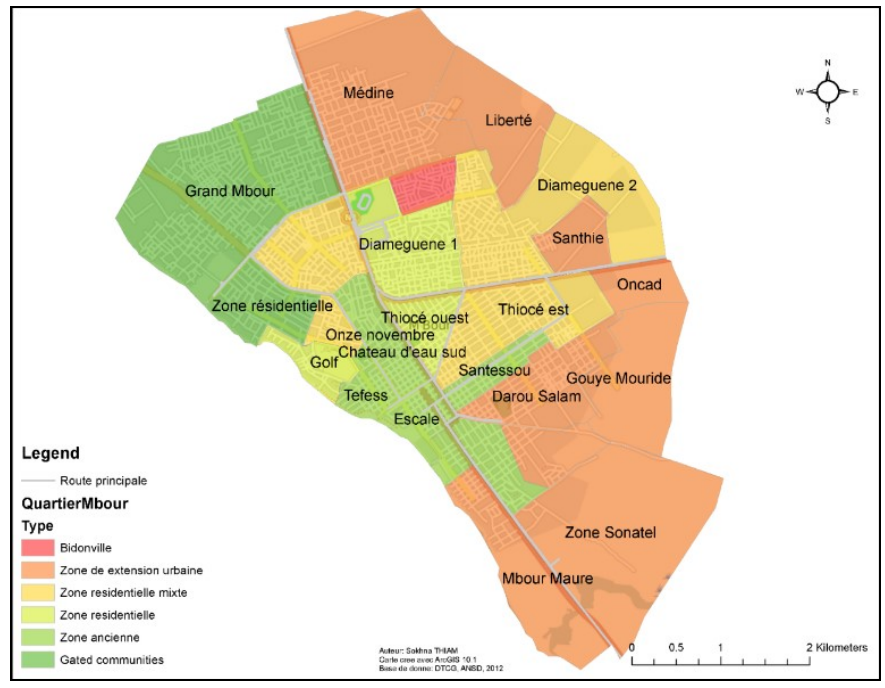

Fig.2. Morphologie urbaine de la ville de Mbour

\subsection{Materials and data}

The geospatial analyses method used to measure the accessibility of the population to five basic urban facilities highlighted in the study requires the use of the following: services (offers), population (potential demand) and the measurement of distance between (accessibility).

\section{The offer: basic urban facilities selected}

To measure the population's access to basic urban facilities in Mbour, multiple data sources were used. Urban equipment such as public standpipes, wells, makets, banks, parking issues of urban taxi, health facilities (health centers, medical centers, hospitals and pharmacy) and schools (primary schools, college, high schools, nursery schools) were being geotagged with a GPs between 2012 and 2013 (Fig. 3). During the study, 241 basic urban facilities 
were identified including 124 water points, 60 schools, 26 health services, 24 economical services and 7 points for urban taxi (Fig. 3).

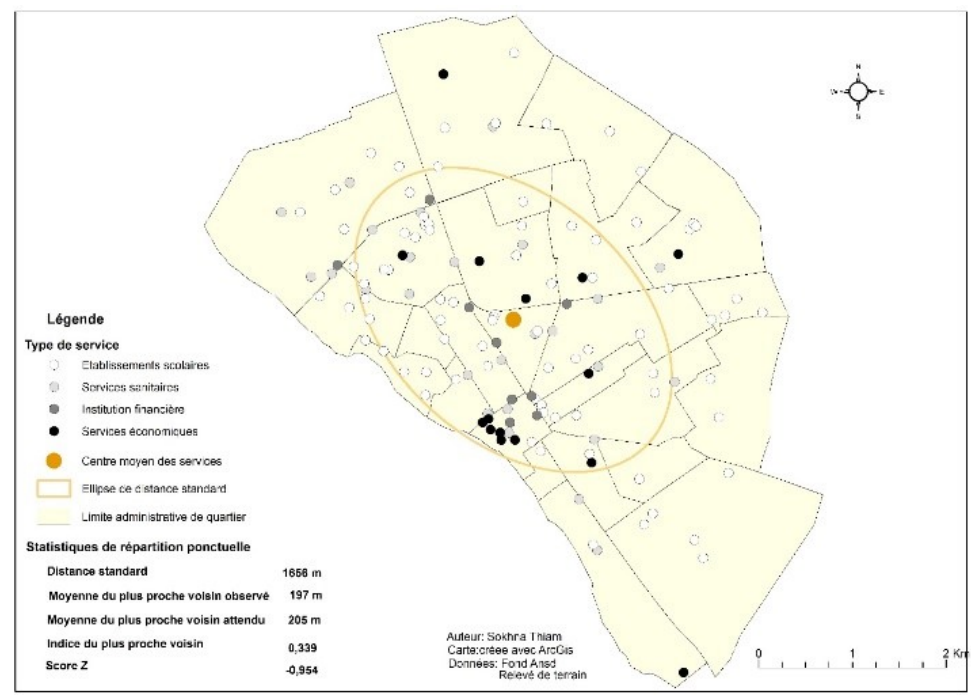

Fig. 1 The potential demand:potential users of basic services

\section{The potential demand:potential users of basic services}

According to the population projection made on the basis of 2002 Census by ANSD Mbour had 223066 inhabitants living in an urban area (1725 ha). In this study we used the district as the unit of analysis since it is the smallest spatial unit used by statistics to disseminate census information. The plots of the database file (houses) inhabited in the city were used to calculate the distance to each home in relation to the nearest service. The spatial boundaries of the parcels (polygons) were transformed into point (feature to point using ArcGIS 10.2).

\section{Distance measurments}

One of the most important parameters in the measurement of the spatial accessibility is the type of distance used to measure the spatial distance between supply and potential The main measures of distances used in the literature are the Euclidean distance (distance in a straight line), distance from Manhattan (total length of both sides of a right triangle at right angles to a grid plan), the distance reticular (length of the shortest path) and the distance / time (fastest computed from a network of streets) (Apparicio et al. 2008). In this study, we use the shortest path through a road network often referred lattice spacing. This 
distance is calculated from the Open Street Map roads (OSM) of the Network Analyst extension of ArcGIS (ESRI, 2005).

1.3. Analyses methods. The output presented in the context of this article consist of descriptive statistics that characterize the concept of accessibility depending on the distance to each type of service; geographical representation reflecting the spatial entry of the studied phenomena and a hierarchical clustering (AHC), which identifies key trends at neighborhood level. For years, planners have studied accessibility of services focusing only on non-spatial aspects, but since the advent of GIS and the spread of aggregated spatial data, there is a new trend service to examine the spatial accessibility disparities to better identify areas with a lack of basic facilities (Apparicio et al, 2008). GIS approaches are the ratio between the number of services and the population census at spatial unit to the distance between the service and the center of survey unit (Ngamini Ngui and Apparicio 2011). In this study, the Closest Facility (from Network Analyst extension) method was used. This method allow us to calculate the real distance to the nearest facility or service (ArcGis, 2012). We calculated the distance of each inhabited house in the city related to the closest facility for five types of selected services. Distance values were normalized to calculate the overall accessibility according to their importance for each type of service. Values were standardized between 0 and 1 to be integrated into a mathematical formula to facilitate the comparison. For general accessibility to health facilities the formula used is written below:

$$
A_{i}=\left(0.35 * B_{j}\right)+\left(0.35 * B_{k}\right)+\left(0.2 * B_{l}\right)+\left(0.1 * B_{m}\right)
$$

\section{$\mathrm{Ai}=$ General Accessibility to health facilities}

$B j=$ normalized values for accessibility to health centers

$B k=$ normalized values for accessibility to hospital

$B 1=$ normalized values for accessibility to health office

$\mathrm{Bm}=$ normalized values for accessibility to pharmacies

We have assign the highest coefficient to the most important service $(0,35$ to hospitals and heath centres according to their importance). In adition, the hierarchical clustered consists of operating a distribution of 25 districts studied in subgroups. In this process, the districts are grouped in phases according to their similarities, until a breakdown between neighborhood groups appears.For this analysis, distance to the five facilities was taken into consideration. All analyzes were performed with Excel, Philcarto and ArcGIS. 


\section{Results and discussions}

2.1. Spatial location of basic urban facilities. Figure 3 highlights the location of basic urban facilities in the city of Mbour in 2013. There is a high concentration of services in districts located in the geographical centre of the city, while the density is not the highest.

The index of nearest neighbor $(0,33)$ confirms this spatial concentration of social services (Bela, 2011). Also, the standard dispersion ellipse around the mean centre of the distribution shows that even if these services seems to be well dispersed on the extent of the city, the majority of these services are closer or within the delimited area by the ellipse (Bela, 2011). The closer the services is is confirmed by the low distances from the average nearest neighbor $(197 \mathrm{~m})$.

\subsection{Mapping and measuring accessibility to urban basic facilities}

-Accessibility to health services. The analysis of accessibility to health services is highlighted by the distance to reach the nearest service. Table 1 shows the distance to be covered for accessing a health service, increasing significantly for the hospital and the health center, and decreases in relation to health stations and pharmacies, while the average score of accessibility decreases. At less than $1 \mathrm{~km}$ for example, 16,335 houses are within the distance to a health post, which represents approximately $73.57 \%$ of apartment houses in the city. The accessibility score ranges here from 0.009 to 0.73 .However, $57.61 \%$ of inhabited houses have access to a pharmacy while $6.99 \%$ of the houses have access to a health center

Table 1 : Demographic accumulation for health services (distance accessibility)

\begin{tabular}{|l|c|c|c|c|}
\hline & $<\mathbf{1 ~ K m}$ & $\mathbf{1} \mathbf{- 2} \mathbf{~ k m}$ & $\mathbf{2} \mathbf{- 3} \mathbf{~ k m}$ & $>\mathbf{3 ~ k m}$ \\
\hline Hospital & 1227 & 3144 & 4250 & 13581 \\
\hline$\%$ & 5,53 & 14,16 & 19,14 & 61,17 \\
\hline Pharmacy & 12790 & 7618 & 1783 & 11 \\
\hline$\%$ & 57,61 & 34,31 & 8,03 & 0,05 \\
\hline Health Centre & 1551 & 5589 & 8460 & 6602 \\
\hline$\%$ & 6,99 & 25,17 & 38,10 & 29,74 \\
\hline Health Post & 16335 & 5278 & 589 & 0 \\
\hline$\%$ & 73,57 & 23,77 & 2,65 & 0 \\
\hline $\begin{array}{l}\text { Accessibility } \\
\text { normalized value }\end{array}$ & & & & \\
\hline Average & 0,19 & 0,62 & 0,46 & 0,37 \\
\hline Ecart-type & 0,11 & 0,09 & 0,15 & 0,10 \\
\hline Minimum & 0,009 & 0,49 & 0,29 & 0,23 \\
\hline Maximum & 0,73 & 0,84 & 0,75 & 0,63 \\
\hline
\end{tabular}


from the same context. There is also evidence for 1 and $2 \mathrm{~km}$; $97.41 \%$ of inhabited houses have at least one health service in their neighborhood. Between 2 and $3 \mathrm{~km}$, however, the accessibility score varies between 0.29 to 0.75 (standard deviation $=0.15$ ) and $19.14 \%$ of the inhabited houses are available at the hospital, $38.10 \%$ the health center and only $2.65 \%$ and $8.03 \%$ respectively to a health center and a pharmacy. More than $3 \mathrm{~km}$, accessibility scores decrease and range from 0.23 to 0.68 .

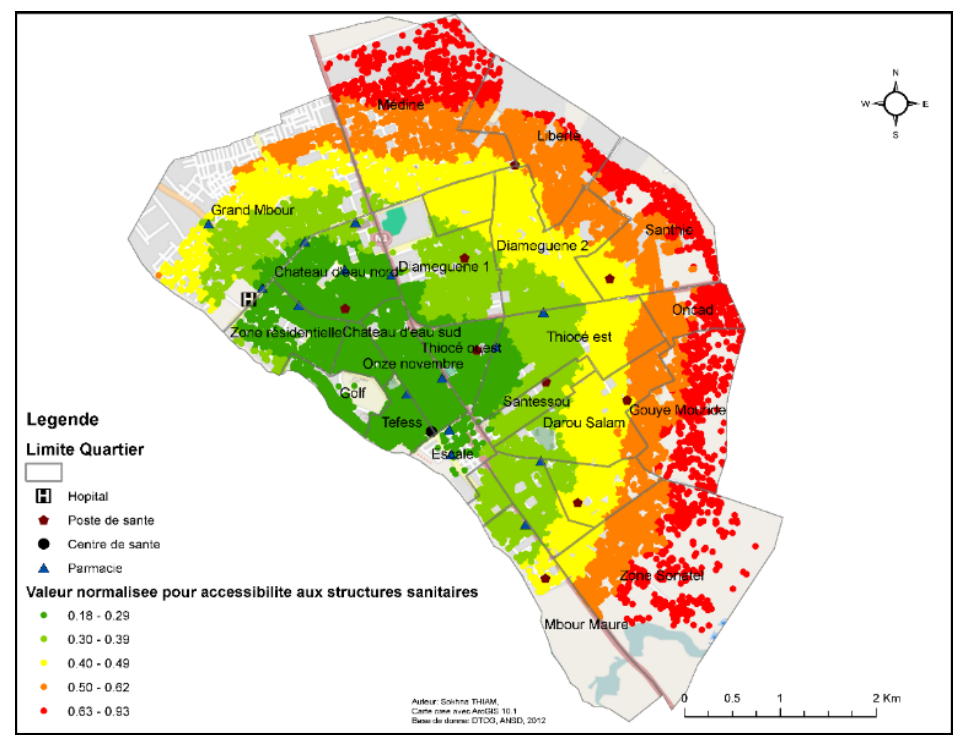

Fig. 2 Accessibility for health services in Mbour

Figure 4 allows to visualize the results of the general accessibility to health services and find spatial disparities of access to these services throughout the city of Mbour, regardless of the distance. In general, potential accessibility to health services is very high in the center and gradually decreases towards the periphery. It is noted however that much of the land inhabited peripheral districts of the northeast and southeast including Medina, Freedom, Santhie, ONCAD, Gouye Mouride and Sonatel area is inaccessible whatever the distance considered. These five districts are the most deprived in health services.

Accessibility to educational services, is analyzed for secondary schools, colleges, primary schools and infant schools. It is clear (as seen in Table 2) that the distance to reach a high school significantly increases and decreases in relation to colleges, primary schools and preschools. At less than $1 \mathrm{~km}, 15772$ inhabited houses have access to at least one middle school, 20761 to a primary 
school $(71,04 \%$ and $93,51 \%)$. The accessibility score ranges here from 0.03 to 0.48 in this context. However, $85.48 \%$ of inhabited houses have access to an infant school while $7.28 \%$ have access to a high school. There is also evidence that between 1 and $2 \mathrm{~km} 62.65 \%$ of inhabited houses have access to a school. Between 2 and $3 \mathrm{~km}$, however, the accessibility score varies 0.28 and 0.72 (standard deviation $=0.04$ ) and $28.78 \%$ of houses have access to a high school for this ray.

Table 2 : Demographic accumulation for educational services (distance-accessibility)

\begin{tabular}{|l|c|c|c|c|}
\hline & $<\mathbf{~ k m}$ & $\mathbf{1 ~ - 2 ~} \mathbf{~ k m}$ & $\mathbf{2} \mathbf{- 3} \mathbf{~ k m}$ & $>\mathbf{3 k m}$ \\
\hline Secondary School & 1616 & 3438 & 6390 & 10758 \\
\hline$\%$ & 7,28 & 15,49 & 28,78 & 48,46 \\
\hline College & 15772 & 5855 & 575 & \\
\hline$\%$ & 71,04 & 26,37 & 2,59 & \\
\hline Elemantary school & 20761 & 1428 & 13 & \\
\hline$\%$ & 93,51 & 6,43 & 0,06 & \\
\hline Preschool & 18979 & 3209 & 14 & \\
\hline$\%$ & 85,483 & 14,454 & 0,063 & \\
\hline $\begin{array}{l}\text { Normalized value } \\
\text { for accessibility }\end{array}$ & & & & \\
\hline Average & 0,23 & 0,39 & 0,35 & \\
\hline Ecart-type & 0,08 & 0,19 & 0,04 & \\
\hline Minimum & 0,03 & 0,13 & 0,28 & \\
\hline Maximum & 0,48 & 0,67 & 0,72 & \\
\hline
\end{tabular}

Figure 5 highlights the results of accessibility to schools. It is an obvious centre-periphery model with an asymmetry for the centre-west side of the city. This good accessibility could be explained by the presence of the school and a number of colleges in this part of the city. 


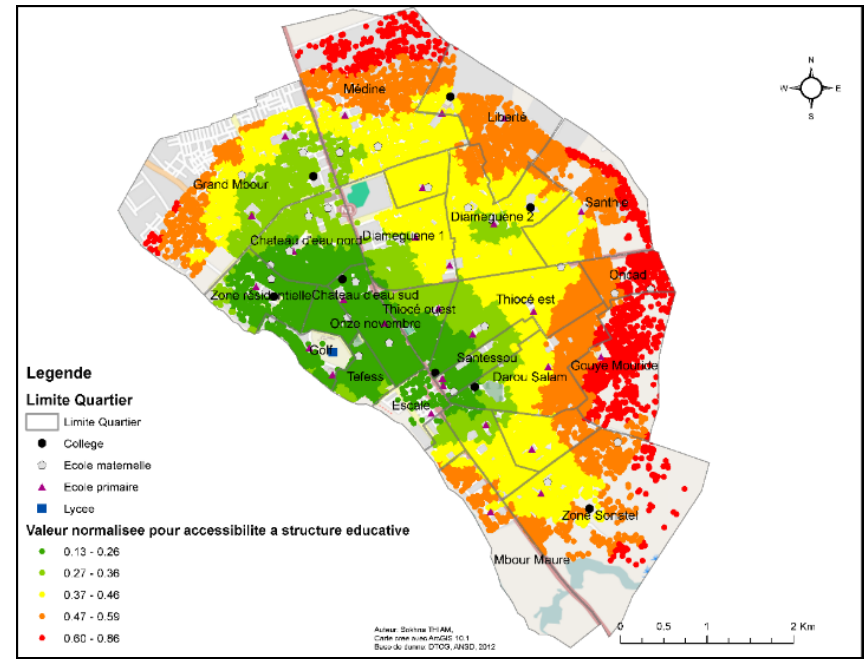

Fig. 3 Accessibility to Educational Services

- Accessibility to economic services, Concerning the economic services such as banks and markets, we observed a high concentration of these services in the neighborhoods near the city centre having a good accessibility. Figure no. 6 shows small values for accessing to services in the north-east and south-east of some peripheric districts sush as Sonatel, Gouye Mouride, Liberte and part of Grand Mbour quartier. The accessibility score values from 0.03 to 1 .

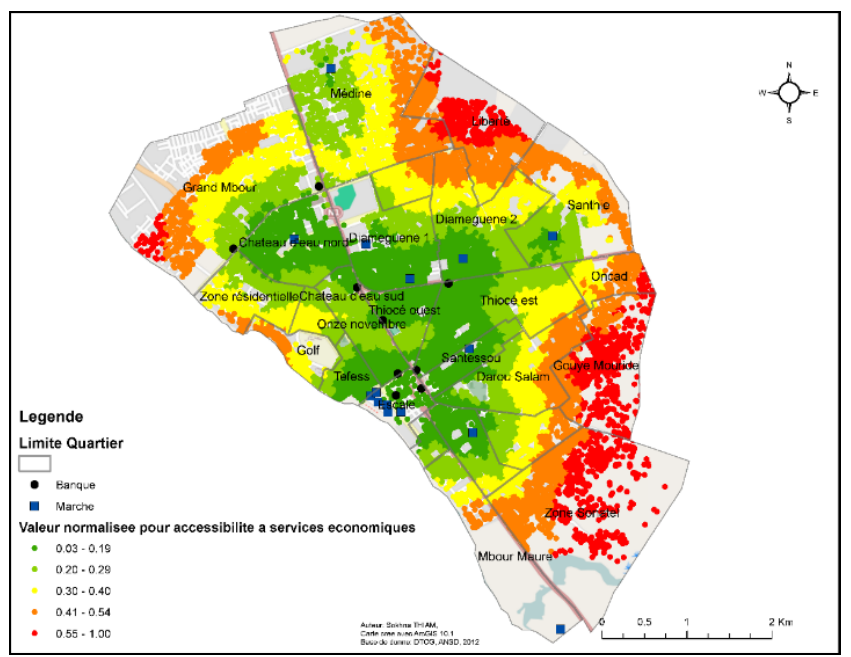

Fig. 6 Accesibility to economic services 
- Access to water sources. The city of Mbour faces enormous difficulties of accessing drinking water sources. Access to drinking water points (wells or standpipes) revealed important intra-district disparities. The service rate is low and the water system does not cover the entire city. About 51 of households are not connected to the water suply network (Toure, 2011). The rapid extension on the city does not match with the urban water suply network which does not reach some suburbs. Inhabitants with no connection either use the water from traditional wells or water standpipes which are to expensive. Howevere, the problem is particularry acute in areas where the proportion oh houses with access to a water point is less than $50 \%$. Figure 7 highlights the accessibility to water points in the city. The houses are grouped in this area as they are the ones that have no connection and those which are not connected to the water network. The map highlights the fragmented structure of access to water sources in the city of Mbour. We have very homogeneous area in the centre with a high concentration of public taps in Onze Novembre, Thioce, Santessou and Darou Salam. The results of the present study allow us to see areas where it would provide priority to the implementation of a social policy of the water to poor neighborhoods or for netwrok expansion. These results highlights the same outputs as data from another study in the same city (Toure, 2011).

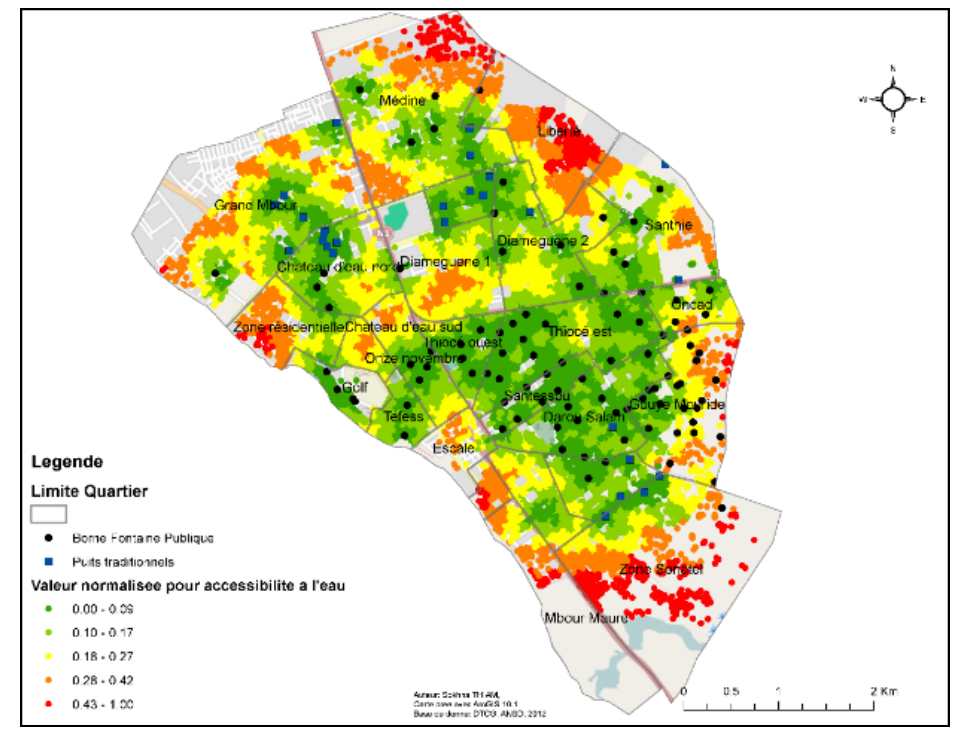

Fig. 7 Accessibility to water sources in Mbour 
Accessibility to urban transport. It appears that, overall, access to paved roads presents differences among inhabited houses. The coverage is relatively reduced as shown in the following map with minimal accessibility of certain peripheral areas. We chose the "clandestine taxis" because it is the only way to transit the city. These types of public transport have seven parking points that connect the city with the outskirts. These clandestine taxis do not cover all areas of the city, they use only the main road. This explains the problem of accessibility of landlocked areas of the city including Zone Sonatel, Mbour Serere Kaw, Darou Salam, Liberte.

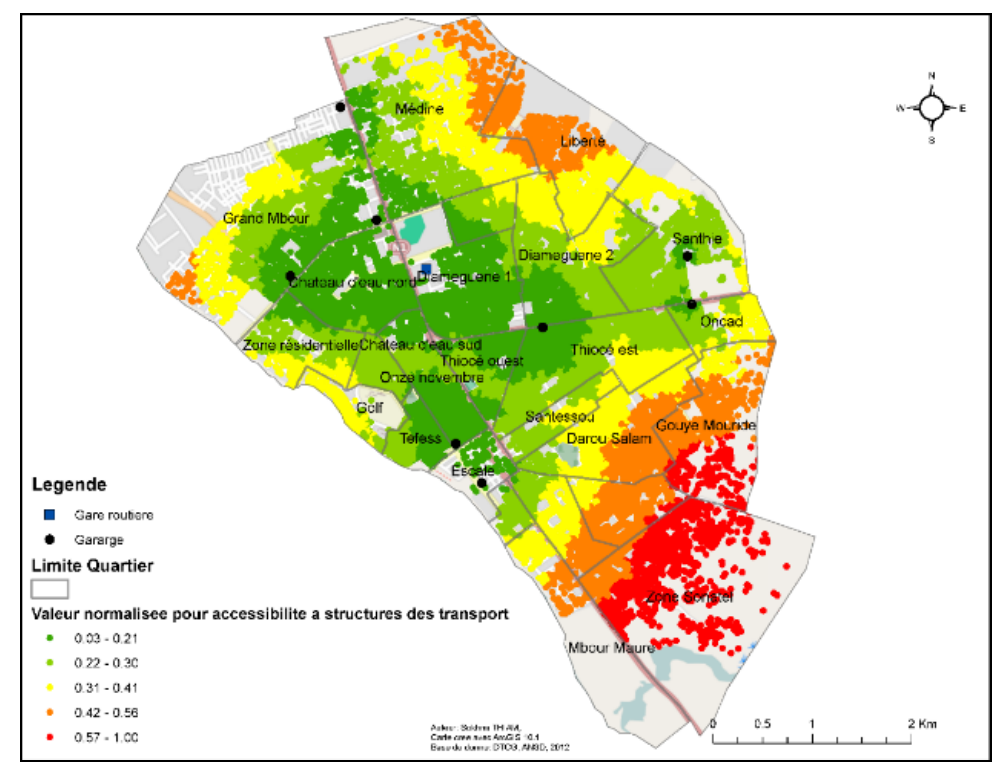

Fig. 8 Accessibility to urban transport

\subsection{General accessibility to basic urban facilities}

Here, we have used the average value for this five indicators to highlight the overall accessibility for each inhabited house. We noted a clear centreperiphery gradient with a good accessibility of central neighborhoods to all basic social services as shown in Figure 9. The score varies between 0.15 and 0.96. Outer districts such as Liberty, Gouye Mouride, Sonatel, Mbour Maure, Medina and Oncad record the lowest values in accessing these basic urban facilities. 


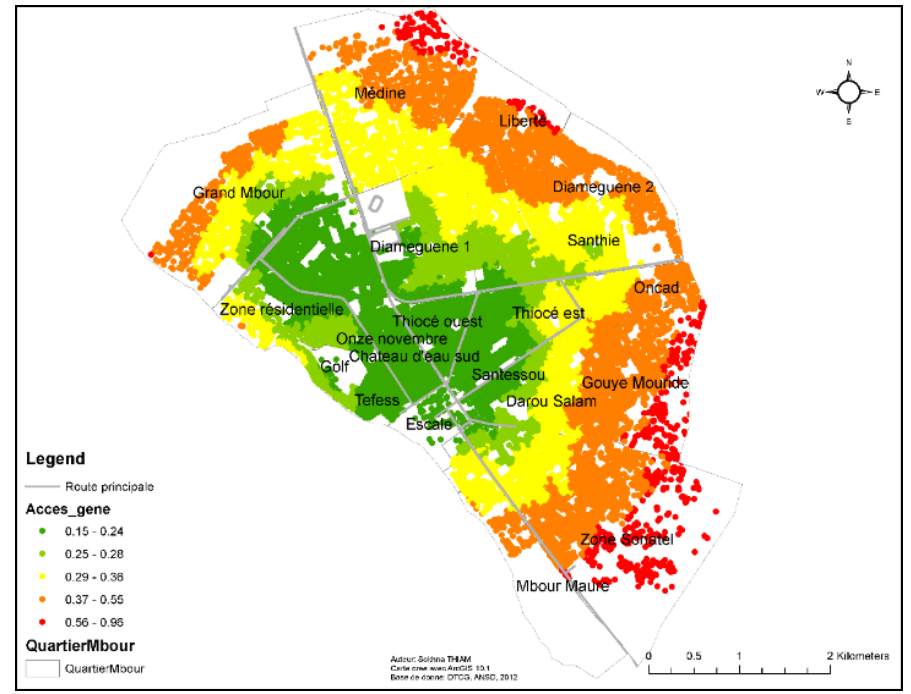

Fig. 9 General accessibility to urban basic facilities for each inhabited house

\subsection{Ascendant hierarchical classification}

For a better understanding of the disparities within the districts we have performed a hierarchical clustering (AHC). The result is a grouping of twentyfive (25) districts studied in five subgroups each characterized by its homogeneity, which reveals a visual score of the area as shown in Figure 11.

The first class includes the districts which covers the west-central part of the city involving coastal districts except the district of Grand Mbour, Mbour Serere Souf and Mbour Maure and part of the peri-central neighborhoods. In this group, the distance values are below the average, which have a good access to all urban basic facilities.

The second class is composed by the rest of the peri-central districts and Grand Mbour. The values are above average for health and educational services. Regarding access to water, the economy and transportation, accessibility values are close to the average.

The third class consists of the districts of Mbour Serere Souf and Mbour Moor. The last two classes together are the most deprived areas, with very low accessibility values for all services. The analysis shows that in Mbour the urban basic facilities are concentrated around the city centre, while some outer districts do not have access to these facilities. This uneven spatial distribution of services goes against the Millenium Development Goald (MDGs) meaning that it increases inequalities for using these services. The high concetration of 
services in urban centre of Mbour was demonstrated by other studies (ANSD, RGPH, projection de la population, 2012). This spatial inequality of the location of basic urban facilities largely explain the spatial disparities in accessing these services.

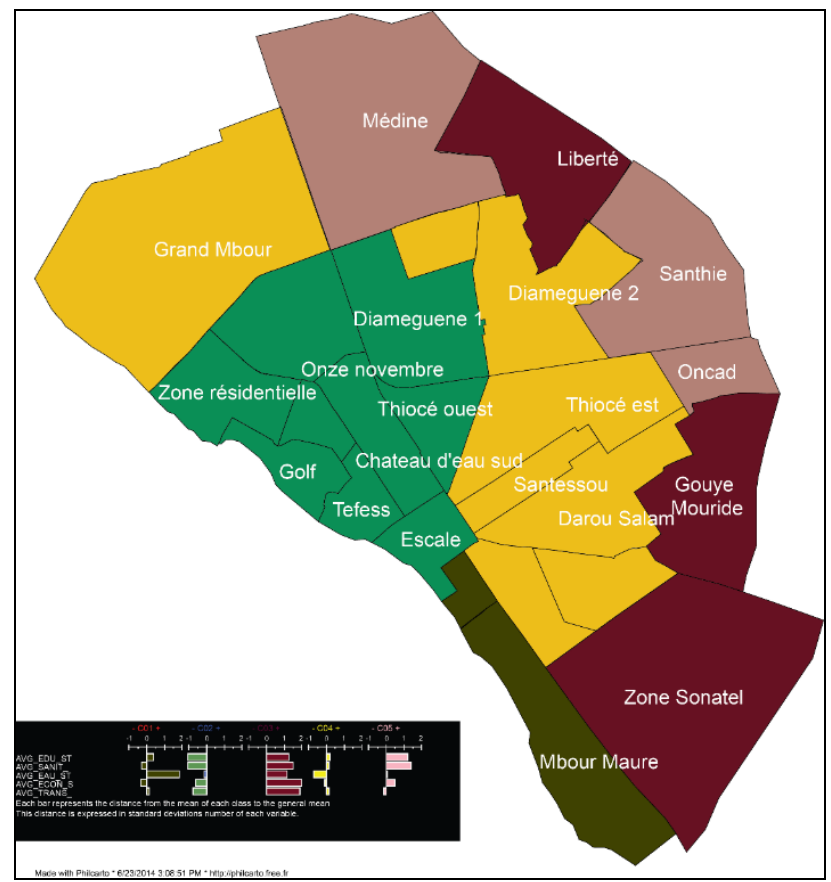

Fig. 41 Ascending hierarchical classification of accessibility to urban basic facilities at district level

Regarding the results from the Figure 9, the issue of accessing the urban basic facilities is a major problem in some peripheral areas of the city. However, looking closely at the accessibility scores and their sparial variation, there is a clear statement fot the centre-periphery model. Moreover, when the distance betwen the inhabited houses to the nearest service increases, the number of available services drops significantly.

\section{Conclusion}

It should be noted that the potential spatial accessibility is not the real accessibility to basic urban facilities, because the last one depends more on several factors including socio-economic status, area of residence, evaluation of 
the services etc. It is possible that high scores for accessibility of some neighborhoods can not enjoy a real and effeective access to services because the real accessibility depends on socio-economic conditions. Howevere, we have not taken into consideration into the present study these socio-economic conditions.

Despite these limitations, the results highlights some strengthen of the study. First, the methodological approach is the one of the strengths of the study, allowing us to identify areas with low accessibility to basic social services in the city of Mbour. This is of vital importance for the planning and management of urban services. Moreover, it reveals the capabilities of the GIS to manage large amount of data over large geographical areas to report on disparities within the same territory with advance level of detail. The use of GIS for modelling the access to urban facilities has not only allowed to view the areas with a lack of facilities but also to show the potential of GIS in research because it would be impossible to visually highlight inequalities in accessing the basic urban facilities with traditional statistical analyses techniques.

Accesibility to urban basic facilities will still be one of the dominant issues in the debate on the management and planning of urban basic facilities in developing countries. It is therefore necesary to develop methodological tools for studiyng the areas which are likely to face a lack of basic facilities. The Closest Facility method seems appropriate for these studies because it measures the spatial accessibility to a much finer scale. This study goes in this direction since it revealed the localization of spatial innequalities for basic urban facilities and uneven accesibility values for theme.

\section{Acknowledgement}

This paper is made and published under the aegis of the Research Institute for Quality of Life, Romanian Academy as a part of programme co-funded by the European Union within the Operational Sectorial Programme for Human Resources Development through the project for Pluri and interdisciplinary in doctoral and post-doctoral programmes Project Code: POSDRU/159/1.5/S/141086.

\section{References}

ANSD. (2012). Cartographie des services sociaux de base. Dakar,Sénégal.

ANSD. (2012). RGPH, projection de la population. Sénégal.

Apparicio, P., Adelmajid, M., Riva, M., \& Shearmur, R. (2008, Mai). Comparing alternative approches to measuring the geographical accessibility of urban health services: Distance type and aggregation error issues. International Journal of Health Geographics, 7. Retrieved Avril 12, 2014, from http://espace.inrs.ca/id/eprint/506

ArcGis, R. C. (2012). ERSI. Retrieved from www.esri.com/Network Analyst. 
Ba, Penda. 1991. La Croissance Urbaine de Mbour À Travers Les Nouveaux Quartiers. Mbour: Maitrise de geographie.

Bela, M. (2011). Spatial Analysis. University of West Hungary, Faculty og Geoinformatics.

ESRI. (2005, Mars). ESRI.ArcGis Network Analyst: Routing, Closest Facility and Service Area Analysis. Retrieved Avril 20, 2014, from esri.com: http://www.esri.com/network analyst

Groza, Octavian. 2005. Bazele Teoretice Ale Planificării Teritoriale. Iași: Editura Universității.

Guagliardo, M. F. (2004). Spatial accessibility of primary care: concept, methods and challenges. International Journal of Health Geogrqphics, 13.

Ngamini Ngui, A., and P. Apparicio. 2011. 'L'accessibilité potentielle aux services de santé mentale à Montréal: approche par les systèmes d'information géographique." Revue d'Épidémiologie et de Santé Publique 59 (6): 369-78. doi:10.1016/j.respe.2011.05.004.

Toure, N. M. (2011). Water-poverty relationships in the coastal town of Mbour (Senegal): Relevance of GIS for decision support. International Journal of Applied Earth Observation and Geoinformation, 7.

Vennetier. (1993). Villes africaines: activités et structures. Presse Universitaire de Bordeaux: CEGET (Centre d'Etude de la Géographie Tropicale). 